\title{
Shaping the Common Labor Market between Denmark and Sweden: Lessons for Sustainable Development
}

\author{
Kate Plaskonis ${ }^{1}$
}

\begin{abstract}
Though Denmark and Sweden have had a similar historical development over the years, the differences in their labor markets have become more visible than ever. While the labor shortage is increasing in Copenhagen, there is a high number of unemployed individuals with a more substantial proportion of vulnerable groups among them in Sweden. Despite some appealing factors (such as less governed labor law, the simplicity of employing and the high wages), the interest of Swedes to work in Copenhagen area has decreased, and as a result, the number of commuters has fallen. Could it then be employers' attitudes towards foreign-born individuals that differ? Through interviewing Swedish and Danish employers and foreign-born population, Fördomsfönster Öresund project investigates if the attitudes differ and how social sustainability and utilizing the existent competence frame a common regional labor market. Interviews show that some concepts might be crucial in addressing the issue: language, prejudice, leadership and the difference in perceptions. By informing and responding to these problem areas, there is a strong possibility of greater integration, competence-based employment and higher revenues in commuting within the region.
\end{abstract}

Keywords: Diversity, competence, social sustainability, labor market, green commuting

\section{Introduction}

The distinct feature of the Nordic model and the social-democratic welfare states has long been generous publicly provided services to the citizens combined with strong economic development, low unemployment and high participation rates in labor market, above all among women (Christensen, 2006). In recent years, the Nordics have faced a number of challenges, such as globalization, new migration patterns, the aging population, growing economic inequalities, and trade competition - all these not only jeopardize the sustainability of the model but also serve as a call for action (Andersen, 2007).

As representatives of the praised Nordic model, Denmark and Sweden have had a similar historical development over the years. Nonetheless, following the rising number of asylum seekers from 2012 and the influx of 2015, countries approached different immigration and integration policies, making differences in their labor market situations more visible than ever. While labor shortage is increasing in the Copenhagen area, there is a high number of unemployed individuals with a more substantial proportion of vulnerable groups among them in Sweden (Nauwelaers et al. 2013; OECD 2015). To preserve the welfare services, labor market policies and positive integration of migrants and refugees are crucial. According to Andersen, the viability of the Nordic model depends on the ratio between productive employment and the workforce demand of a large public service sector, along with the need to produce the tax base and revenues for states expenditures, like welfare services and pensions (2007). 
This paper focuses on possible solutions to create a sustainable model of social- and labor market integration and the differences in how Sweden and Denmark approach foreign-born competence, as well as how businesses can respond to growing inequalities within societies.

\section{Beyond the Skills}

Traditional research on labor market integration is often conducted through the lens of the human capital model (Becker 1975), where the level of human capital (formal education, labor-market experience, and skills acquired at work) determine how successful and demanded an individual is in terms of employment. The theoretical framework has been of late extended by social capital suggestions, as well as other aspects like admission status and discrimination. They contribute widely to explaining some of the models of immigrant labor-market integration (Irastorza and Bevelander 2017) and, therefore, are applicable in understanding the alternate development of Denmark's and Sweden's labor market situations.

Despite some appealing factors (such as less governed labor law, the simplicity of employing and the high wages), the interest of Swedes to work in Copenhagen area has decreased, and as a result, the number of commuters in Oresund region has fallen. This research believes that there might be another reason that prevents vulnerable groups, specifically foreign-born individuals, from searching for jobs within the Oresund region, rather than in the residence country. Moreover, this reason is seldom economical but is socio-cultural. Addressing the positive integration of foreign-born/second generation Swedes and the idea of the common labor market, the language and cultural differences between Sweden and Denmark might hinder individuals to look for a job across the bridge.

\section{Methodology}

The paper utilized up-to-date interviews and findings from Fördomsfönster Öresund project to answer the research questions. Fördomsfönster Öresund is a threeyear project, partly financed by Interreg, between non-governmental and non-profit organization MINE, Lund University, Copenhagen University, the NORDEN Association and the independent news agency Øresundsinstituttet. The project aims to investigate whether employers' attitudes towards hiring foreign-born individuals and second-generation migrants differ between Denmark and Sweden. The project focuses on understanding the mental barriers that exist through interviewing 100 Swedish and Danish companies, as well as 100 foreign-born or second-generation Swedes and Danes. The project believes that the analysis of interviews will illustrate a comprehensive picture of how the labor market looks for the foreign-born population and what actions companies can take to utilize existent competence.

It is important to note that the project is ongoing. At this point, 22 Swedish companies in different sectors and 50 foreign-born participants have been interviewed, which only provides a fragment of the intended study. Nonetheless, the results provide a substantial ground to map and analyze employers' attitudes to foreign-born labor, their thoughts on 
how to frame a positive labor market integration and what hinders people from looking for a job across the bridge. The owners of the project MINE and NORDEN Association have a broad network of their member companies, which were the first choice when conducting the interviews. Qualitative methodology is used in the analysis of the interviews and the three-component model, also called the $\mathrm{ABC}$ model, presents the foundation for the interview design. Unlike the early beliefs that only actions can determine people's attitudes to things, the model emphasizes the importance of considering people's experience. The three-component model gives the opportunity to understand the notion of attitude with the help of three components: "Affect," "Behavior" and "Cognition (Rosenberg and Hovland 1960). In this project, the interview questions provide a combined understanding of the participants, what they know, how they act and react. Notably, the components can contradict each other; a person can be aware of facts but not always act accordingly (Shatski 2002).

\section{Results}

Based on the received answers, employers are appealed by the idea of the regional and sustainable labor market, matching the existing competencies with a labor shortage and how crucial it is for growth and social sustainability. Employers have stated that equal opportunities for everyone and non-discrimination in their recruitment process are the guaranteed practices in almost all interviews. During interviews, many companies reflected on how they work and what they could do better. At one company where both HR and sustainability managers participated in the interview, three people began to ask each other questions, taking notes and consulting the interviewer regarding diversity and inclusion practices. In general, it seemed as Swedish companies were opened to embrace foreign-born labor.

Nevertheless, the research identified three areas affecting the employment of foreignborn individuals or second-generation migrants: language skills, lack of appropriate leadership and different perceptions of the issue between the public and private sector.

\subsection{Language}

Many employers reflected over the importance of the Swedish language in the workplace and how problematic it might be to hire someone who does not possess the required language skills. Even the companies which have English as their working language emphasized that Swedish is prevalent during the coffee breaks and small talks.

"Despite our new campaign where different ethical groups are presented, it is important to speak Swedish internally," stated one of the interviewed managers.

There is fair ground to having a common language in the workplace as it produces a working culture within the organization, which is one of the company's factors of success. Nonetheless, can it be the perception that migrants (with second-generation migrants among them) who search for jobs cannot handle Swedish well enough? Is it taken for granted, as a prejudged fact which contradicts employers' statements on equal opportunities for all? (Rydgren 2004) 


\subsection{Leadership}

A lot of company representatives expressed that the executives are not willing or not active in promoting diversity and inclusion at the working place, which results in more homogeneous working groups. While leadership plays one of the central roles in establishing welcoming and competence-based employment, it seems like there is strong misbalance between the engagement of the employees and the executive board. 16 out of 22 companies responded that they believe there should be done more from executive representatives in terms of framing inclusion and diversity at the working place.

One of the CEOs described the situation in his company as following:

"We do not see any value in adapting the workplace to people with special needs, ethnicities since we are a homogeneous group. You would typically see three guys in white shirts and jeans talking in front of the coffee machine. It is like we need a slap in terms of diversity. I mean, we have chosen a multicultural city of Malmo for its' energy, but it just does not exist in our workplace".

\subsection{The difference in perception between the public and private sector}

Surprisingly, representatives from the private and public sector had a different perception of whether it is difficult or easy to get employed as a foreign-born. Employees of municipalities believed that it is not problematic.

"It is effortless to find a job in our city. However, it is hard for an employer to maintain these people because it requires a lot of effort and patience from the employer" concluded one of the participants.

Is it the difference in perception or do foreign-born individuals have better opportunities for employment in the public sector?

When it comes to the interviewed foreign-born individuals, many claims that finding a job that responds their skill level is hard, and they must fight hard to get an interview opportunity.

\section{Discussion}

While the research focus is the unveiling of employers' attitudes towards the foreign-born population, the research findings demonstrate what concrete actions are required in terms of positive integration of the latter.

There is a common belief among employers that language skills play a crucial role when employing foreign-born individuals. Investing in, and increasing, the human capital through education and language training of migrants in Sweden is essential to positive integration (Redfern 2017). In practice, however, Swedish language courses have often been criticized for their inefficiency and high retention numbers. They lack a definite presence of companies and municipalities when designing the framework for language education, something Denmark successfully implemented in their IGU (integration education) process (Karlsdóttir et al. 2017).

At the same time, the issue of language brings the importance of avoiding employers' prejudgments that lead to the loss of competence. Assuming that second-generation migrants, born in the country, possess the required language skills and knowledge about norms, culture and how things are done, they should not become a subject to statistical 
discrimination (Rydgren 2004). As stated earlier, allowing and encouraging companies to be a part of the integration process is important - they should be present at the early stage of designing educational standards, getting to know the target group (whether it is high-skilled migrants or analphabets), collaborating with other actors on the issue. Employers should be aware of unconscious bias and how to recognize and reflect on them. Otherwise, they will end up with vague cliché statements on equal treatment and recruitment. The part of the solution is highly connected to the issue of leadership.

The issue of positive integration is a matter of social sustainability and requires new sustainable leadership. Paper findings demonstrate that many employers lack this kind of leadership and as a result, there is a high level of unemployment among vulnerable groups. The paper suggests four categories of leadership development practice, as a response to the matter.

Developed by Cambridge Institute of Sustainability Leadership, the model involves implementing diversity and inclusion (as a part of social sustainability) into companies' DNA, its' strategies (2013). The model will allow on leadership engagement, employee awareness, empowering the champions (experts on the issue within the company) and executive development. Earlier Boxenbaum and Battilana have made a case study on three key business actors in Denmark and how the strategic execution of diversity management transformed into a managerial practice that meets society's economic and cultural conditions (2005). Therefore, finding collaborations and investing in diversity management could be one of the solutions for cutting down on unemployment.

Another issue highlighted by the paper is other perceptions on employment possibilities for foreign-born individuals between private sector employees and their colleagues in the public sector. In contradiction to the human capital model, migrants experience a substantial downgrading of their skills as they start working at openings below their competence. When investigating the issue more closely, it appears that experiences differ significantly depending on what sector they work. Those employed by National Health Service, for instance, have more positive experiences than those who operate within private sector where, despite high-skill proficiency, they mostly work as care assistants (Kofman and Raghuram 2006).

At the same time, the success of positive integration (or at least the perception of it) can be explained by public sector having the largest concentration of employees who are "militantly multicultural" (Duffy and Frere-Smith 2014). This group is positive about nearly every aspect of immigration: they see the value in economic and cultural input of the foreign-born population and are "twice as likely as average to employ immigrants" (ibid).

Attaining data from the private and public sector in Denmark would be next step in analyzing if there are significant differences in attitudes between sectors, and how these differences can contribute to the integrated labor market in Oresund, and utilization of competence.

\section{Conclusion}

The integrated labor market in Oresund and the maintenance of the praised Nordic model can result in obtaining the benefits of agglomeration economies by 
creating a larger metropolitan region (OECD 2013). Nevertheless, it requires adaptation to modern challenges. The strong and growing economies of Sweden and Denmark have enough space to welcome new workers if they respond to the notion of positive integration.

Integrating foreign-born individuals and second-generation Swedes into the Swedish labour market will, therefore, be largely dependent on several aspects: how effectively the language courses are designed and implemented, the transition towards new sustainable leadership and finding best practice scenarios/collaborations from private and public sectors.

\section{References}

Andersen, T. (2007). The Nordic model. Helsinki: The Research Institute of the Finnish Economy.

Becker, G. (1975). Human capital. New York: National Bureau of Economic Research.

Boxenbaum, E., \& Battilana, J. (2005). Importation as innovation: transposing managerial practices across fields. Strategic Organization, 3(4), 355-383. doi: 10.1177/1476127005058996

Christiansen, N. F., K. Petersen, N. Edling, and P. Have (2006). The Nordic Model of Welfare: A Historical Reappraisal. Copenhagen: Museum Tusculanum.

Irastorza, N. and P. Bevelander. (2017). The Labour Market Participation of Humanitarian Migrants in Sweden: An Overview. Intereconomics, 52(5), 270-277. doi: 10.1007/s10272-017-0689-0

Kofman, E. and P. Raghuram (2006). "Women and global labour migrations: Incorporating skilled workers." Antipode, Vol. 38, No. 2, pp. 282-303.

Nauwelaers, C., K. Maguire and G. Ajmone Marsan (2013). "The case of Oresund (Denmark-Sweden) Regions and Innovation: Collaborating Across Borders," OECD Regional Development Working Papers, 2013/21, OECD Publishing. http://dx.doi.org/10.1787/5k3xv0lk8knn-en

OECD (2013). Regions and Innovation: Collaborating across Boarders, OECD Reviews of Regional Innovation. OECD Publishing. http://dx.doi.org/10.1787/9789264205307-en

OECD/European Union (2015) Indicators of immigrant integration 2015: Settling in. OECD Publishing, Paris

Redfern, T. (2017). The Integration of Refugees into the Swedish Labour Market: Policies and Outcomes. Retrieved from https://www.academia.edu/32759384/The_Integration_of_Refugees_into _the_Labour_Market_in_Sweden_Integration_Policies_Outcomes_and_Impacts

Rosenberg M. J. and C. I. Hovland, "Cognitive, Affective and Behavioral Components of Attitudes." (1960). In M. J. Rosenberg, C. I. Hovland (eds.), Attitude Organization and Change: An Analysis of Consistency Among Attitude Components. New Haven: Yale University Press

Rydgren, J. (2004). Mechanisms of exclusion: ethnic discrimination in the Swedish labour market. Journal Of Ethnic And Migration Studies, 30(4), 697-716. doi: 10.1080/13691830410001699522

Schatzki T R (2002). The Site of the Social: A Philosophical Account of the Constitution of Social Life and Change (Penn State University Press, University Park, PA) 